\section{GUIDELINES AND PRACTICE}

Guideline Review, a new section by Harry Baumer, debuts in this issue of $A D C$. Guidelines are part of the world of evidence based medicine. They come in many different forms, and are released by various groups, including professional societies and governmental agencies. Recently, recommendations have been developed for both assessing and reporting guidelines. ${ }^{12}$ The key attributes of good guidelines include a clear focus, systematic review of the literature, definitions of unfamiliar terms, grading of evidence, and when possible, inclusion of patient preferences. Guidelines should be dated. A recent report indicates that $50 \%$ of guidelines are invalid six years after publication. ${ }^{3}$ We recognise that guidelines themselves do not change practice; however, they often contain important information for practitioners, and can be used as a blueprint for the basis of quality improvement efforts.

I hope you find the Guideline Review section helpful. In general, we will only report on high quality guidelines, and will include the level of evidence in each review. Although we recognise that changing practice entails more than just publishing the highlights of guidelines, we hope that by making them more readily available it will be easier to assimilate them into practice. See page 1126

\section{ENVIRONMENTAL HEALTH}

The past decade has seen renewed interest in the impact of the environment on children's health-in part because we better understand the movement of pollutants through the environment, can better measure exposure (tissue, hair, and urine samples) and effect (from $\mathrm{T}$ and $\mathrm{B}$ cell function to social, emotional, and cognitive functioning), and because there is increasing recognition that many adult diseases begin during childhood. In a fascinating historical report Dr John Black, who worked at The Hospital for Sick Children, Great Ormond Street, describes admission for intussusception in the years before and after the great London smog of 1952. The rate of admission seemed to increase during the four day period during which the whole of London was affected. This report clearly illustrates that environmental health is not a new concept, but rather an evolving one. The world's recent preoccupation with the SARS epidemic, reflecting the speed and ease of international air travel, illustrates how public health officials now recognise that the traditional concept of environmental health has changed.

Children are exposed to the environment through air, soil, food, and water-all of which may contain threats to their health. The obvious concerns of air pollution persist, but new interest in the impact of housing, food additives, genetically engineered food, potential allergens, and exposure to tiny amounts of pesticides and insecticides, are all novel areas of investigation.

See page 1040

\section{COMPLEMENTARY AND ALTERNATIVE MEDICINE}

Patients have always sought care and remedies outside of traditional medicine. However, there is now a greater appreciation that clinicians need to be more aware of complementary and alternative medicine (CAM) as practised by their patients. One area of concern is herbal medicines. In an original report (Ramsay and colleagues) and a commentary (Choonara) the potentially harmful addition of corticosteroids to herbal creams is described and discussed. Whether all herbal medicines and homeopathic remedies should come under government regulation is being debated in the US. This would significantly expand the powers and responsibilities of the Food and Drug Administration, and likely slow the growth of the expanding market for alternative medicines.

I am struck by the relationship between culturally competent care and CAM. In both the UK and US when people refer to culturally competent care, they generally are referring to differences in race and ethnicity between provider and patient, and the need for clinicians to be aware of how culture and ethnicity influence patientphysician interaction and decision making. Little is said or written about the differences in socio-economic status between clinicians and patients, which in many instances are quite substantial. Obviously, even if there are no ethnic, racial, or socio-economic differences between provider and patient, being aware of the use of CAM is important. In the past when our children got sick they would come into our bedroom (this inevitably occurred in the middle of the night) and ask my wife for a remedy. She is a self trained homeopath. In addition, once a year they continue to go for their routine chiropractic check up (she pays the bill). Our paediatrician, a friend and colleague, has never asked this well educated woman about her use of CAM with our children.

See page 1056

\section{REFERENCES}

1 Shaneyfelt TM, Mayo-Smith MF, Rothwangl J. Are guidelines following guidelines? The methodological quality of clinical practice guidelines in the peer-reviewed medical literature. JAMA 1999:281:1900-1905.

2 Shiffman RN, Shekell P, Overhage M, et al. Standardized reporting of clinical practice guidelines: a proposal from the conference on guideline standardization. Ann Intern Med 2003;139:493-498.

3 Shekelle PG, Ortiz E, Rhodes S, et al. Validity of the Agency for Healthcare Research and Quality clinical practice guidelines. JAMA 2001;286:1461-1467.

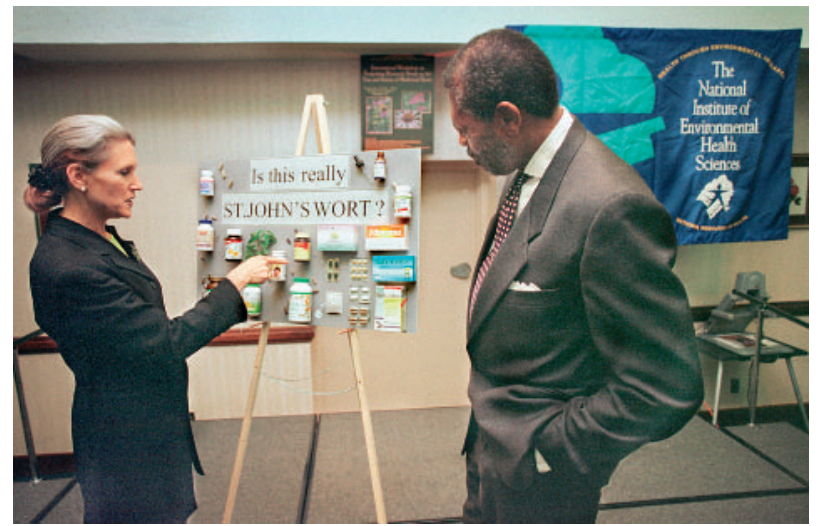

Photograph courtesy of Wagner International. 